Article

\title{
Hegemony of Digital Platforms, Innovation Culture, and E-Commerce Marketing Capabilities: The Innovation Performance Perspective
}

\author{
Amira Khattak (iD)
}

check for updates

Citation: Khattak, A. Hegemony of Digital Platforms, Innovation Culture, and E-Commerce Marketing Capabilities: The Innovation Performance Perspective. Sustainability 2022, 14, 463. https:// doi.org/10.3390/su14010463

Academic Editor: Zhenzhong Ma

Received: 4 November 2021

Accepted: 27 December 2021

Published: 2 January 2022

Publisher's Note: MDPI stays neutral with regard to jurisdictional claims in published maps and institutional affiliations.

Copyright: (C) 2022 by the author. Licensee MDPI, Basel, Switzerland. This article is an open access article distributed under the terms and conditions of the Creative Commons Attribution (CC BY) license (https:// creativecommons.org/licenses/by/ $4.0 /)$.
Department of Marketing, College of Business Administration, Prince Sultan University, Riyadh 11586, Saudi Arabia; akhattak@psu.edu.sa; Tel.: +966-114948074

\begin{abstract}
Advanced technologies have affected business models. Sustainable innovation performance has become very critical for the survival of businesses, in particular in emerging economies. Therefore, this study aims to investigate the impact of digital platforms, innovation culture (IC), and e-commerce marketing capabilities on innovation performance (IP). In this study, the intervening role of IC was studied. Furthermore, the moderating role of e-commerce marketing capabilities was studied regarding the link between digital platforms and IP. Data were collected from the top management of small and medium enterprises (SMEs) working in several cities in Pakistan. For the data collection and analysis, the quantitative research method was used. Correlation, regression, and bootstrap methods were applied to test hypotheses. The results showed that digital platforms have positive impacts on innovation culture and IP. The findings verified that IC plays a mediating role in the relationship between digital platforms and IP. Moreover, digital platforms increase IP in the presence of e-commerce marketing capabilities. SMEs employ a self-motivated perspective, and it is necessary to evaluate their performance in terms of innovation. Subsequently, businesses that innovate their services and products with respect to their customers' demands have the capacity to achieve true success. Consequently, SMEs need to analyze their IP for their businesses to flourish. The study emphasizes the overlooked relation of digital platforms and IP, as well as demonstrates the mediation effect of IC.
\end{abstract}

Keywords: digital platforms; innovation culture; e-commerce marketing capabilities; innovation performance; SMEs

\section{Introduction}

Organizational innovativeness has received great attention among practitioners and researchers alike [1]. Advanced technologies coupled with dynamic environments exert pressure on businesses to adopt innovative technologies and processes [2]. It is only by innovation; in particular advances in technology, that traditional businesses are able to convert to modern businesses in the current digital and knowledge-based economies [3,4]. However, the complexity associated with technological dynamism and e-commerce development makes organizational survival challenging [3]. Even under such challenging circumstances, innovation and the resultant transformation cannot be neglected due to their major role in influencing the success and high performance of organizations [5], in particular SMEs.

SMEs are defined on the basis of their sales volume and number of employees [5]. In Pakistan, SMEs are defined by the Small and Medium Enterprises Development Authority (SMEDA) in terms of their fruitful assets and different numbers of employees. Small businesses are defined to as businesses having 10-50 employees, while medium businesses as having 51-99 employees. What makes SMEs more vulnerable in circumstances of technological dynamism is the resource constraints. Consequently, IP represents actual 
challenges for all firms in general and especially SMEs [5]. Although business model transformations represent great opportunities for success; these also represent challenges, especially for SMEs. The main challenges are related to both the adoption and successful implementation of digital technologies. Nevertheless, regardless of the challenges, SMEs critically require the innovation of their business processes to increase their e-commerce activities, technical expertise, and IP [5], as well as the development of digital platforms, leveraging their available e-commerce resources [6,7].

Digital platforms play a vital function in the survival of businesses with respect to environmental and technological challenges [8]. Digital platforms are technologies used by organizations to allow them to standardize, distribute, and edit data at an unparalleled scale [9]. Digital platforms aid in revolutionizing the way firms obtain a competitive advantage [10]. Digital platforms play a large role in the innovation of organizations processes by providing them with valuable information [11]. Digital platforms allow new ideas to innovate a firm's product/services via aligning its commodities strategically with the foundation of its activities [12].

The literature has highlighted several outcomes of digital platforms such as businesses' financial performance [13], network capability [8], customer value creation [14], and improvisation capability and organizational readiness [15]. However, the most exciting outcome of digital platforms in terms of IC and IP has been overlooked so thus far. This research looks to measure digital platforms as a favorable asset that enables a firm to achieve great success in terms of their IP [15].

The current study was conducted to understand digital platforms and to ascertain their positive impacts on IP in the presence of different supporting factors. Digital platforms have a critical role in the improvement of organizational IP [16]. In the current study, the intervening role of IC was also investigated. Sattayaraksa and BoonItt [17] defined innovation culture as a "set of the beliefs and shared values inside enterprise that help in discovering novel opportunities for the development of innovation" (p. 733).

IC enables management to use new information to explore knowledge, find opportunities, and bring innovation to a firm [18]. Scholars, such as Aksoy [19] and Ghasemzadeh et al. [20], have recognized that IC performs as a facilitator of IP. IC works as a bridge between digital platforms and IP. IC assists organizations in exploring new opportunities and knowledge to perform innovation activities relating to their products or processes. At the same time, e-commerce marketing capabilities play a critical role to enhance IP. Through their e-commerce marketing capabilities, organizations are able to increase their information and knowledge about the market, their suppliers, and their competitors [21]. This valuable information contributes to the decisions about innovation activities [22-24]. While scholars have presented several outcomes of e-commerce marketing capabilities, however, studies have lacked any related proof about the moderating effect of e-commerce marketing capabilities. Therefore, in the current study, the moderating effect of e-commerce marketing capabilities on the association between digital platforms and IP was investigated.

The objective of this study is to draw an IP model for SMEs to discover the impact of digital platforms on IP. The study assesses the mediating effect of IC on the relationship between digital platforms and IP. The current study also assesses the moderating role of e-commerce marketing capabilities on the relationship between digital platforms and IP. In the next section of this investigative study, the literature relating to the study variables is briefly discussed along with the associated hypotheses developed. The subsequent part of the work discusses the data collection process and the tools and techniques employed. The results of the analysis and measurements and the conclusion are presented in the following part. In the final part, the theoretical and practical implications are also extensively observed and compared to test the hypotheses. 


\section{Literature Review}

\subsection{Digital Platforms and Innovation Performance}

Digitalization boosts the importance of digital technology in the operative actions of business firms [25]. Williams et al. [26] suggested that organizations use digital technologies that allow them to quickly receive and distribute the increasing volume of information and knowledge. According to Mikalef and Pateli [27], a digital platform represents the ability of a firm to deploy information and communication technologies together with internal and external resources.

Digital platforms enable organizations to improve intra- and inter-organizational communications $[24,28,29]$. Specifically, digital platforms help the formalization and centralization of information among several actors of an organization [30].

Conversely, innovation activities are mainly based on the creation of novel information, which increases from both the internal and external resources of firms [16]. SMEs with structured digital platforms are likely to generate new ideas and formulate and put into practice these innovation activities [15,31], which improves the IP of the firms. As a result, in the current study, the first hypothesis is formulated as follows:

Hypothesis 1 (H1). Digital platforms significantly predict innovation performance.

\subsection{Digital Platforms and IC}

Digital platforms help firms acquire important information and knowledge from several internal and external resources [32]. Alternatively, IC refers to shared values and beliefs that ensure the utilization of the obtained information to form new opportunities [17]. Digital platforms play a critical role in establishing IC by providing the required information. According to Aksoy [19], firms are inclined to innovate through advanced technologies and obtain information regarding supplies, customers, and market competitors.

Digital platforms provide the infrastructure for the exchange of information among organizational members that permits exploring novel means of conducting business to satisfy the demands of customers [33,34].

SMEs along with sound technical resources communicate with outside partners and thus become capable of advancing their IC $[31,35,36]$. In accordance with these arguments, the second hypothesis is formulated as follows:

Hypothesis 2 (H2). Digital platforms are positively associated with IC.

\subsection{Innovation Culture and IP}

Existing studies highlight that organizations achieve IP with the help of their infrastructure, which helps in the creation and implementation of innovation activities [18,33,37]. Thus, IC forms a setting by which members of the organization can search for new opportunities to invent and implement different ways of doing business [38]. IP is the frequency of exploring opportunities to convey the change in business processes and products [20]. IC allows SMEs to search and use information and knowledge to achieve innovation effectiveness and efficiency in order to improve IP [19,39].

Padilha and Gomes [40] said that a culture of an organization that facilitates innovative actions is likely to participate in the creativeness and development of its IP markets. IC infrastructure allows SMEs to promote their creativeness and innovation activities in their firms $[39,41,42]$. Thus, the third hypothesis is formulated as follows:

Hypothesis 3 (H3). Innovation culture has a positive connection with innovation performance.

\subsection{Mediating Role of Innovation Culture}

Digital platforms and their application turn out to be the resources of the latest information and knowledge of the organization [13]. Similarly, IC permits the organiza- 
tion to search for opportunities that help develop innovation activities mainly based on digital platforms.

It is obvious that the digital platforms of SMEs give the necessary information for the formulation of the innovation activities within the organization [8]. Therefore, this study suggests that IC plays a mediating role between the digital platforms and the IP of SMEs. The majority of business organizations are gaining an increased advantage due to their digital platforms, due to the latest technologies and highly developed means of communication for the promotion of IC $[35,36]$.

IC assists in the utilization of the obtained information to augment the IP of SMEs through novelty in both the businesses' processes and products [19,39]. The digital platforms of SMEs provide a chance to obtain a variety of information from different stakeholders [19]. Digital platforms boost IC to attain IP. The digital platforms facilitate SMEs in building relations with business associates in the development of advanced to innovate its processes and products, which eventually improve IP [15,31]. Therefore, it is argued that digital platforms have a foundational function for IC, which consecutively enhances the IP of SMEs. The fourth hypothesis is as follows:

Hypothesis 4 (H4). Innovation culture plays a mediating role between the digital platforms and innovation performance.

\subsection{Moderating Role of E-Commerce Marketing Capabilities}

Marketing capabilities are processes through which organizations pick value-propositions and are able to organize available resources to deliver those value-propositions [43]. Accordingly, from an information systems viewpoint, enterprises that mix and integrate different resources for the execution of e-commerce activities create far-reaching, unique e-commerce capabilities [44]. Joining both information systems and a tactical marketing perspective, e-commerce marketing capabilities refer to the ability of a firm to develop, integrate, and recognize e-commerce processes to offer value-propositions that meet the desired objectives. Through their e-commerce marketing capabilities, organizations achieve their e-commerce objectives, for instance: online promotion, providing an online product catalogue, participating in an e-commerce marketplace, online payments, and e-fulfilment [45].

Digital platforms are critical for the development of organizations' e-commerce marketing capabilities and enable them to align existing marketing capabilities with their e-commerce activities [46].

Previous research showed the progressive function of digital platforms for developing the e-commerce marketing capabilities of an organization (e.g., [46,47]). E-commerce marketing capabilities play the role of moderator between digital platforms and IP. The digital platforms of an organization have been conceded to have a key effect on the execution of e-commerce activities online and lead the organization towards IP [46]. This research work proposes that with a strong relationship between digital platforms and IP, the moderating effect of e-commerce marketing capabilities cannot be ignored. E-commerce marketing activities help firms engage in successful e-commerce processes and increase their IP.

Hypothesis 5 (H5). The association between digital platforms and innovative performance is moderated through e-commerce marketing capabilities.

\subsection{Theoretical Framework}

Figure 1 demonstrates the relationships among the study constructs. The four variables are as follows: digital platforms are an independent variable; innovation culture is a mediating variable; e-commerce marketing capabilities are a moderating variable; IP is the dependent variable. 


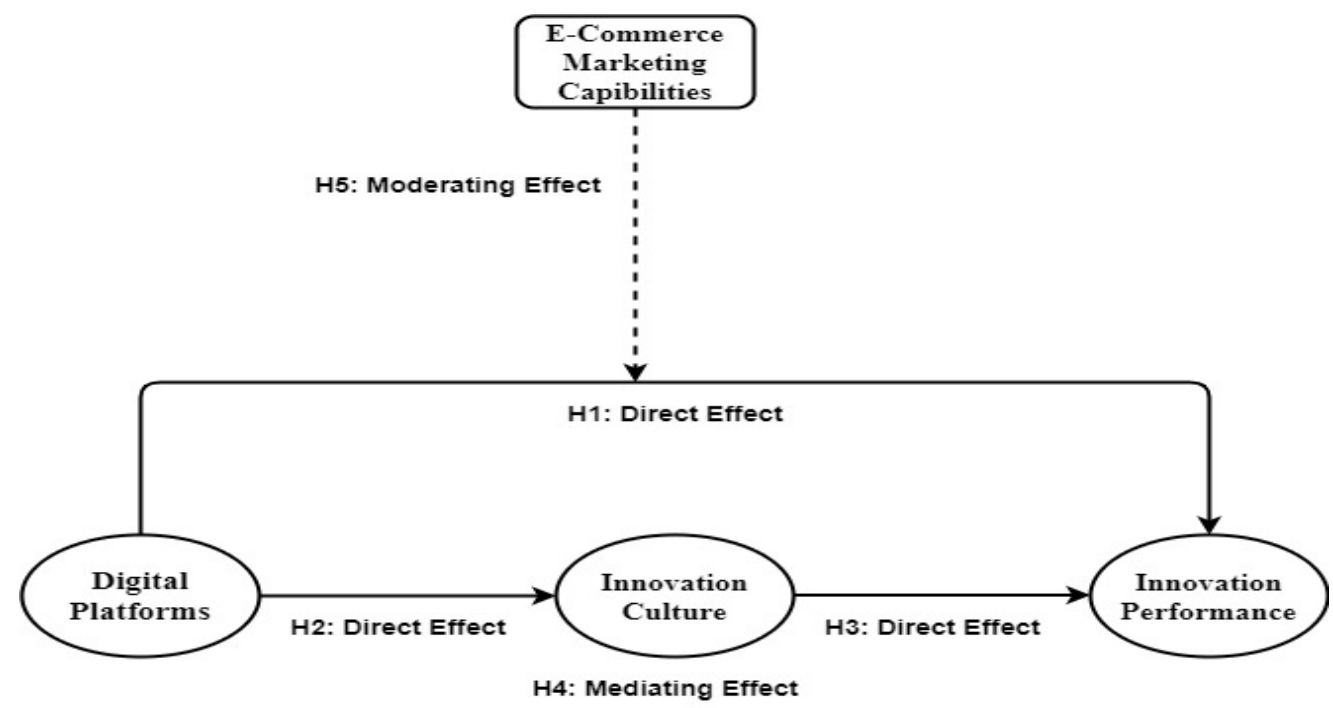

Figure 1. Theoretical framework.

\section{Methodology}

\subsection{Data Collection and Participants}

Data were collected through a cross-sectional research method once and at a specific time. The list of the SMEs for the sample was acquired from the Small and Medium Enterprises Authority (SMEDA). In the present study, an online survey design was used for the data collection from the owners/managers of the SMEs working in several large cities in Pakistan. A random sample of 609 was selected for data collection, and 509 expressed their formal agreement to take part in this survey. Those participants who formally agreed to participate in this survey were given an information sheet, which gave the promise of confidentiality, a statement describing the aim of this research, and information about the key constructs of the present study.

Data were collected in 2 rounds with a 1 month lag. Information about the exogenous variables and demographic factors, such as age, education, gender, and work experience, was gathered first. Data about the mediator, moderator, and outcome variable were gathered in the second round of data collection [48,49]. 387 completed replies were gathered during the 3 months of the data collection process. The information was investigated using SPSS 25.0 and the structural equation modeling of SMEs in AMOS 25.0.

In terms of gender, $74.68 \%$ of the respondents were male and $25.32 \%$ were female. The respondents' average age was 38 years. The biographical details of the respondents are provided in Table 1.

\subsection{Measurement}

Table 2 presents the information about the measurement scale used in the current study.

\subsubsection{Digital Platforms}

Digital platforms are the online platforms that not only link multiple business firms but also help organizations streamline their communication process, which benefits all organizations engaged [48]. The digital platforms were measured on an 8-item scale adapted from [48]. The items generated an $\alpha$-value of 0.82 .

\subsubsection{Innovation Culture}

IC was used as the intervening variable in the current study and measured by a sixitem scale formulated by Terziovski [49]. The construct of IC generated an $\alpha$-value of 0.79 . 
Table 1. Characteristics of the survey sample $(n=387)$.

\begin{tabular}{|c|c|c|c|}
\hline \multicolumn{2}{|c|}{ Work Experience in Years } & \multicolumn{2}{|c|}{ Business Age in Years } \\
\hline 1 to 5 & $95(24.54 \%)$ & 1 to 5 & $156(40.31 \%)$ \\
\hline 6 to 10 & $124(32.04 \%)$ & 6 to 10 & $112(28.94 \%)$ \\
\hline 11 to 15 & $99(25.98 \%)$ & 11 to 15 & $58(14.98 \%)$ \\
\hline 16 to 20 & $18(4.65 \%)$ & 16 to 20 & $29(7.49 \%)$ \\
\hline More than 20 & $51(13.17 \%)$ & More than 20 & $32(8.26 \%)$ \\
\hline \multicolumn{2}{|c|}{ Business Category and No. of Firms } & \multicolumn{2}{|c|}{ Education Level } \\
\hline Furniture and fixtures & $69(17.82 \%)$ & 0 High school or less education & $16(4.13 \%)$ \\
\hline Chemicals & $60(15.50 \%)$ & 1 Intermediate education & $78(20.15 \%)$ \\
\hline Pharmaceutical & $48(12.40 \%)$ & 214 y education & $74(19.12 \%)$ \\
\hline Office machinery & $66(17.05 \%)$ & 316 y education & $211(54.52 \%)$ \\
\hline Machinery and equipment & $64(16.53 \%)$ & 4 More than 16 y education & $08(2.06 \%)$ \\
\hline Electrical machinery & $41(10.59 \%)$ & & \\
\hline Transportation material & $39(10.07 \%)$ & & \\
\hline \multicolumn{2}{|c|}{ Business Size (No. of Employees) } & \multicolumn{2}{|c|}{ Gender } \\
\hline 0 More than 50 & $(35.05 \%)$ & 0 Male & $289(74.68 \%)$ \\
\hline 1 More than 100 & $(64.95 \%)$ & 1 Female & $98(25.32 \%)$ \\
\hline
\end{tabular}

Table 2. Discriminant accuracy of the construct.

\begin{tabular}{llllll}
\hline & Items & Cronbach's Alpha & Factor Loading & Composite Reliability & AVE \\
\hline Digital Platform & 8 & 0.82 & $0.73-0.91$ & 0.87 & 0.68 \\
Innovation Culture & 6 & 0.79 & $0.70-0.88$ & 0.92 & 0.71 \\
E-commerce MC & 8 & 0.86 & $0.76-0.90$ & 0.94 & 0.73 \\
IP & 11 & 0.81 & $0.71-0.93$ & 0.90 & 0.69 \\
\hline
\end{tabular}

\subsubsection{Innovation Performance}

The 11-item scale created by Alegre and the Chiva [50] for the measurement of IP was used. This scale is composed of two dimensions: innovation efficacy and innovation efficiency. A 7-item scale measures innovation efficacy, and a 4-item scale measures the efficiency of innovation. With the help of the additive index, a single overall measure of IP was created, and this single measure of IP generated a Cronbach's $\alpha$-value of the 0.81 .

\subsubsection{E-Commerce Marketing Capabilities}

The moderating variable of e-commerce marketing capabilities was measured through an 8-item scale adapted from Burd [45] and Prasad et al. [47]. This resulted in a Cronbach's $\alpha$ of 0.86 . The details of the measurements scale are provided in Appendix A.

\section{Results}

Various statistical techniques were used for the analysis of the collected data. These techniques consisted of descriptive statistics, correlation coefficients, regression coefficients, and SEM. Furthermore, the "Process" approach developed by Preacher and Hayes was applied to test the mediation. Subsequently, to evaluate the model fitness, four different models were used. Table 3 portrays the results.

\subsection{Correlation Results}

Table 4 demonstrates the results of the correlation and descriptive statistics. These results proved the current study's hypotheses, and all variables were positively associated with the dependent variable. 
Table 3. CFA results.

\begin{tabular}{lllllll}
\hline Model Detail & $\chi^{\mathbf{2}}$ & Df & $\chi^{\mathbf{2}} / \mathbf{d f}$ & RMESA & GFI & CFI \\
\hline Hypothesized four-factor model & 1021.34 & 390 & 2.619 & 0.06 & 0.91 & 0.92 \\
Three-factor model & 1174.65 & 360 & 3.263 & 0.15 & 0.88 & 0.89 \\
Two-factor model & 1244.58 & 310 & 4.015 & 0.22 & 0.71 & 0.72 \\
Single-factor model & 1236.21 & 290 & 4.263 & 0.26 & 0.64 & 0.65 \\
\hline
\end{tabular}

Table 4. Correlation and descriptive statistics.

\begin{tabular}{lllllllllll}
\hline Constructs & Mean & SD & $\mathbf{1}$ & $\mathbf{2}$ & $\mathbf{3}$ & $\mathbf{4}$ & $\mathbf{5}$ & $\mathbf{6}$ & $\mathbf{7}$ & $\mathbf{8}$ \\
\hline Gender & 0.9 & 0.81 & 1 & & & & & & & \\
Age & 33 & - & 0.09 & 1 & & & & & & \\
Work experience & 2.9 & 0.84 & 0.08 & 0.03 & 1 & & & & & \\
Education level & 2.4 & 0.91 & 0.06 & 0.05 & 0.04 & 1 & & & & \\
Digital platforms & 3.8 & 0.93 & 0.09 & $0.12^{*}$ & 0.08 & 0.07 & 1 & & & \\
Innovation culture & 3.5 & 0.91 & 0.05 & 0.09 & 0.04 & 0.05 & $0.32 * *$ & 1 & & \\
IP & 3.9 & 0.95 & 0.03 & 0.07 & 0.06 & 0.09 & $0.21^{*}$ & $0.30^{* *}$ & 1 & \\
E-commerce MC & 3.6 & 0.90 & 0.08 & 0.03 & 0.04 & 0.09 & $0.25^{* *}$ & $0.23^{*}$ & $0.17^{*}$ & 1 \\
\hline
\end{tabular}

Note: ${ }^{*} p<0.5$; ${ }^{* *} p<0.1$; SD, standard deviation; IP, innovation performance; MC, marketing capabilities.

Digital platforms are positively associated with IC $(\mathrm{r}=0.32 * *)$, e-commerce marketing capabilities $\left(\mathrm{r}=0.25^{* *}\right)$, and IP $\left(\mathrm{r}=0.21^{* *}\right)$. IC is associated with IP positively $\left(\mathrm{r}=0.30^{* *}\right)$ and e-commerce marketing capabilities $\left(\mathrm{r}=0.23^{* *}\right)$. Similarly, the e-commerce marketing capabilities are positively linked with IP $\left(r=0.17^{* *}\right)$.

\subsection{Hypothesis Testing}

Structural equation modeling (SEM) was used to test the hypotheses in this study. The findings verified that positive relationships existed among all variables. Please refer to Table 5 . The digital platforms positively and significantly predicted IP $\left(B=0.22{ }^{* *}\right)$; therefore, $\mathrm{H} 1$ of the study was accepted. Digital platforms were significantly connected positively with IC $\left(B=0.33^{* *}\right)$; thus, $\mathrm{H} 2$ was also accepted. IC was positively linked with IP $(B=0.32 * *)$; thus, $\mathrm{H} 3$ was further accepted.

Table 5. Hypothesis testing.

\begin{tabular}{llll}
\hline Hypothesis Detail & Effects & Coefficient & Remarks \\
\hline (H1) Digital platforms $\rightarrow$ innovation performance & + & $0.22^{* *}$ & Accepted \\
(H2) Digital platforms $\rightarrow$ innovation culture & + & $0.33^{* *}$ & Accepted \\
$\begin{array}{l}\text { (H3) Innovation culture } \rightarrow \text { innovation } \\
\text { performance }\end{array}$ & + & $0.32^{* *}$ & Accepted \\
\hline Note: ${ }^{* *} p<0.1$ & & &
\end{tabular}

\subsection{Mediation Effect of IC between Digital Platforms and IP}

For the mediation test, Preacher and Hayes's approach was utilized [51]. Table 6 presents the mediation-related results between digital orientation and digital innovation. The results clearly showed IC's mediating role between IP and digital platforms. Moreover, the results of the Sobel test analysis "Z-score" value $\left(5.74^{* *}\right.$ ) was significant; thus, H5 was accepted. 
Table 6. Results of the indirect effect of digital platforms.

\begin{tabular}{lllllll}
\hline Model Detail & Data & Boot & Bias & SE & Lower & Upper \\
\hline $\mathrm{DP} \rightarrow \mathrm{IC} \rightarrow \mathrm{IP}$ & 0.1471 & 0.1463 & -0.0008 & 0.329 & 0.1894 & 0.2222 \\
\hline Sobel Test & & & & & \\
Z-Score $=5.74$ & \\
& & & & \\
Note: ${ }^{* *} p<0.1 ;$ DP, digital platforms; IC, innovation culture; IP, innovation performance.
\end{tabular}

\subsection{Moderating Role of E-Commerce Marketing Capabilities on the IC and IP Link}

Hierarchical regression analysis was conducted to observe the moderating effect of e-commerce marketing capabilities on the relationship between digital platforms and the IP. The findings of the hierarchical regression analysis are presented in Table 7 using the procedures of Step 1, Step 2, and Step 3. The base model information is depicted in Steps 1 and 2 in Table 7. Furthermore, Step 3 presents the coefficients of moderation of the e-commerce marketing capabilities on the relationship between digital platforms and IP. Table 7 also presents the coefficient of the interaction term, i.e., digital platforms' ecommerce marketing capabilities, which indicated that e-commerce marketing capabilities positively affect the connection between digital platforms and IP $(\beta=0.24, p<0.01)$. As per the proposal of Aiken et al., slope analysis was also conducted. Figure 2 reveals that digital platforms increase IP in the presence of e-commerce marketing capabilities.

Table 7. Outcomes of moderation analysis using hierarchical regressions.

\begin{tabular}{lccc}
\hline & Step 1 & Step 2 & Step 3 \\
\hline \multicolumn{2}{l}{ Moderation of e-commerce marketing capabilities } & & \\
\hline Gender & 0.028 & 0.010 & 0.009 \\
Age & 0.023 & 0.020 & 0.017 \\
Work experience & 0.007 & 0.005 & 0.006 \\
Educational level & 0.033 & 0.034 & 0.043 \\
Digital platforms & & $0.30^{* *}$ & $0.33^{* *}$ \\
E-commerce marketing capabilities & & $0.22^{* *}$ & $0.26^{* *}$ \\
\hline Digital platforms' e-commerce marketing capabilities & & $0.24^{* *}$ \\
\hline $\mathrm{R}^{2}$ & 0.009 & 0.191 & 0.198 \\
Adjusted $\mathrm{R}^{2}$ & 0.003 & 0.159 & 0.175 \\
$\Delta \mathrm{R}^{2}$ & 0.007 & 0.163 & 0.028 \\
$\Delta \mathrm{F}$ & 4.172 & 79.63 & 17.13 \\
\hline
\end{tabular}

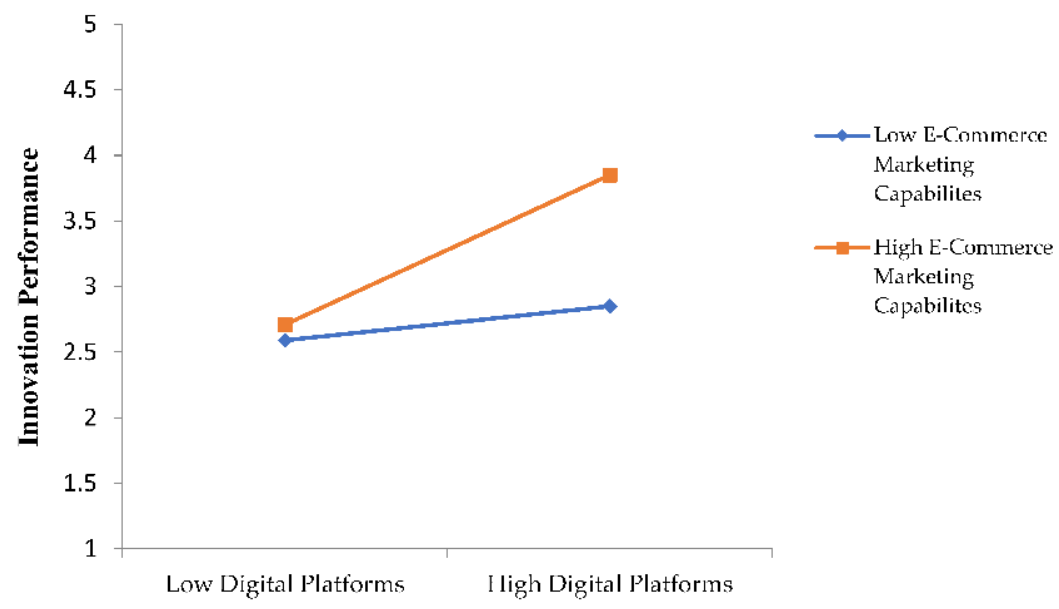

Figure 2. Slope analysis. 


\section{Discussion}

This study's purpose was to understand how digital platforms add to the development of IP via IC. To this purpose, this study linked digital platforms to IC and IP. Moreover, the mediation effect of IC between digital platforms and IP was also tested. The moderating role of e-commerce marketing capabilities in the relationship between digital platforms and IP was also tested.

To achieve this study's objectives, five hypotheses were designed. These hypotheses were used to explore the connection among digital platforms, IC, e-commerce marketing capabilities, and IP. Regarding H1, a positive relationship between the digital platforms and IP was proposed. The findings revealed that digital platforms allow firms to acquire valuable information, which provides the foundation to increase their IP. The results showed the positive effect of digital platforms on IP. These outcomes are consistent with previous research, i.e., $[15,31]$.

The results also revealed that $\mathrm{H} 2$ was confirmed, as digital platforms significantly predicted IC. These findings suggested that digital platforms are the leading force behind the improvement of IC. These results are consistent with $[35,36]$. The current study also proposed that IC has a positive relationship with IP. The results confirmed H3, as IC significantly predicted IP. The results of this study are consistent with the findings of preceding researchers [41,42]. These results propose that an innovation climate assists firms to become widely involved in innovation activities to improve their IP.

Regarding H4, the results confirmed that digital platforms predict innovation via IC. Digital platforms provide the necessary innovation information and knowledge about the infrastructure for the innovation activities to improve the IP of the business. The results revealed that enterprises with innovation information have robust IC, which consecutively increases the IP of the organization. In conclusion, H5 proposed a moderating role of e-commerce marketing capabilities on the relationship between digital platforms and innovation performance. These findings showed that the effect of IC on IP is moderated by e-commerce marketing capabilities.

\subsection{Theoretical Contribution}

This study has several valuable theoretical contributions to innovation management research. The main input of this study was to test the exceptional role of digital platforms as a determinant of IC and IP, particularly in the context of SMEs. This pioneering research evidenced a comprehensive explanation for boosting the IP of SMEs, which was not previously sufficiently appreciated in recent research or literature.

Second, the current study adds to the existing body of research on the IP model for the SME sector. The IP model shows how the integrated essential aspects of a business, e.g., digital platforms, IC, and e-commerce marketing capabilities, determine IP.

Third, this analysis indicates a review of digital platforms in developing IC. IC is an important mechanism of organizations regarding exploring new opportunities that support innovation $[19,39,41,42]$. There is limited debate on the role of IC in their determinants and outcomes. Therefore, to fill the gap in previous knowledge, this study focused on digital platforms as a potential determinant of IC and IP as the outcome of IC.

\subsection{Practical Implications}

This study has important practical implications. Firstly, this study suggested that firms can improve their IP with the help of digital platforms via IC. By doing so, IP can only be achieved when organizations have strong IC and resources for the required information. Furthermore, for the formulation of the best strategies for innovation, digital platforms can be considered a far better response to the dynamic environment of IP [15].

Second, this study suggested that digital platforms act as the foundation of IC. Therefore, the response to various demanding e-commerce activities is ultimately strong IP, further cementing that management must have a focus on the digital platforms. 


\subsection{Conclusions}

The basic objective of the study was to investigate the role of digital platforms, ecommerce marketing capabilities, and innovation culture (IC) in the improvement of the IP of SMEs. Furthermore, the current study also highlighted the mediation effect of IC between digital platforms and IP. Beyond the mediating role of IC, the moderating role of e-commerce marketing capabilities was also tested regarding the link between digital platforms and IP. This study's findings revealed that digital platforms positively impact IC and IP. The findings verified that IC plays a mediating role in the linkage between digitalplatforms and IP. Moreover, e-commerce marketing capabilities moderate the relationship between digital platforms and IP.

This study had a few limitations that might provide future research directions. The current study was conducted on SMEs located in various large cities in Pakistan only; however, future research may include some other economies to generalize the findings of this research. Furthermore, the data from SMEs were taken; hence, some other industries may be taken as future research. The relational impact of digital platforms on IC and IP was only investigated through quantitative analysis; however, data may be taken and analyzed through qualitative techniques for further insights into the study variables. The current study applied a cross-sectional design to test the hypothesized model; however, a longitudinal design can be used to understand the impact of digital platforms on IP via IC.

Funding: The author would like to acknowledge the support of Prince Sultan University for paying the article processing charges (APC) of this publication.

Data Availability Statement: Not available due to confidentiality reasons.

Acknowledgments: The author would like to acknowledge the support of Prince Sultan University for paying the article processing charges (APC) of this publication.

Conflicts of Interest: Author declares no conflict of interest.

\section{Appendix A}

\section{Digital Platforms}

1. We access data through digital platform easily as of our partners' of the IT systems

2. Our platform provides seamless connection between our partners' IT systems and our IT systems (e.g., forecasting, production, manufacturing, shipment etc.)

3. Our platform has the capability to exchange real-time information with our partners

4. Our platform easily aggregates relevant information from our partners' databases (e.g., operating information, business customer performance, cost information etc.)

5. Our platform is easily adapted to include new partners

6. Our platform can be easily extended to accommodate new IT applications or functions

7. Our platform employs standards that are accepted by most current and potential partners

8. Our platform consists of modular software components, most of which can be reused in other business application

\section{Innovation Culture}

1. Our culture rewards behaviors that relate to creativity and innovation

2. Our organization's culture encourages informal meetings and interactions

3. Our culture encourages employees to monitor their own performance

4. Employees take risks by continuously experimenting with new ways of doing things

5. Our culture encourages employees to share knowledge

6. Our culture focuses on teamwork long term performance

\section{E-Commerce Marketing Capabilities}

1. Provide Online Product/Service Catalogue to Customers

2. Promote and advertise company's products, services and capabilities 
3. Online ordering of products/services

4. Presenting and paying bills online (e.g., paying bills, being payed)

5. Enable salespeople online access to product/price/performance information

6. Ordering supplies online (e-procurement)

7. Participating in an electronic market place

8. Fulfilling and/or delivering online-e-fulfilment (e.g., software)

\section{Innovation Performance}

1. Replacement of the products are being phased

2. Extension of the product wide range in product field by new products

3. Wide range of main products are introduced in outside

4. Environment friendly services and products are developed

5. Evolution of market share

6. To open market in abroad

7. New domestic groups are targeted to open

8. Innovation project contain average development time

9. Innovation project has average numb of the working-hours

10. Per project of innovation has average cost.

11. Satisfaction of the Global degree with project efficiency in innovation.

\section{References}

1. Lin, F.-J.; Lin, Y.H. The effect of network relationship on the performance of SMEs. J. Bus. Res. 2016, 69, 1780-1784. [CrossRef]

2. Lestari, S.D.; Muhdaliha, E.; Putra, A.H.P.K. E-Commerce Performance Based on Knowledge Management Organizational Innovativeness. J. Distrib. Sci. 2020, 18, 49-58.

3. Beyari, H. Recent E-Commerce Trends and Learnings for E-Commerce System Development from a Quality Perspective. Int. J. Qual. Res. 2021, 15, 797-810. [CrossRef]

4. Fichman, R.G.; Dos Santos, B.L.; Zheng, Z. Digital innovation as a fundamental powerful concept in the information systems curriculum. MIS Q. 2014, 38, 329-A15. [CrossRef]

5. Curado, C.; Muñoz-Pascual, L.; Galende, J. Antecedents to innovation performance in SMEs: A mixed methods approach. J. Bus. Res. 2018, 89, 206-215. [CrossRef]

6. Karić, L.; Lazović Pita, L.; Peštek, A.; Pijalović, V.; Činjarević, M. Heading out SMEs to the e-commerce highway. Management 2021, 26, 3-20. [CrossRef]

7. Muslikhin, M.; Horng, J.R.; Yang, S.Y.; Wang, M.S.; Awaluddin, B.A. An Artificial Intelligence of Things-Based Picking Algorithm for Online Shop in the Society 5.0's Context. Sensors 2021, 21, 2813. [CrossRef]

8. Cenamor, J.; Parida, V.; Wincent, J. How entrepreneurial SMEs compete through digital platforms: The roles of digital platform capability, network capability ambidexterity. J. Bus. Res. 2019, 100, 196-206. [CrossRef]

9. Williamson, B. Making markets through digital platforms: Pearson, edu-business, the (e) valuation of higher education. Crit. Stud. Educ. 2021, 62, 50-66. [CrossRef]

10. Parker, G.; Van Alstyne, M.; Choudary, S.P. Platform Revolution: How Networked Markets Are Transforming the Economy How to Make Them Work for You, 1st ed.; W. W. Norton \& Company: New York, NY, USA, 2016.

11. Cenamor, J.; Rönnberg Sjödin, D.; Parida, V. Adopting a platform approach in servitization: Leveraging the value of digitalization. Int. J. Prod. Econ. 2017, 192, 54-65. [CrossRef]

12. Freixanet, J.; Braojos, J.; Rialp-Criado, A.; Rialp-Criado, J. Does international entrepreneurial orientation foster innovation performance? The mediating role of social media open innovation. Int. J. Entrep. Innov. 2021, 22, 33-44. [CrossRef]

13. Kazan, E.; Tan, C.-W.; Lim, E.T.K.; Sørensen, C.; Damsgaard, J. Disentangling digital platform competition: The case of UK mobile payment platforms. J. Manag. Inf. Syst. 2018, 35, 180-219. [CrossRef]

14. Matarazzo, M.; Penco, L.; Profumo, G.; Quaglia, R. Digital transformation customer value creation in Made in Italy SMEs: A dynamic capabilities perspective. J. Bus. Res. 2021, 123, 642-656. [CrossRef]

15. Jun, W.; Nasir, M.H.; Yousaf, Z.; Khattak, A.; Yasir, M.; Javed, A.; Shirazi, S.H. Innovation performance in digital economy: Does digital platform capability, improvisation capability organizational readiness really matter? Eur. J. Innov. Manag. 2021. [CrossRef]

16. Scuotto, V.; Del Giudice, M.; Carayannis, E.G. The effect of social networking sites absorptive capacity on SMES' innovation performance. J. Technol. Transf. 2017, 42, 409-424. [CrossRef]

17. Sattayaraksa, T.; Boon-Itt, S. CEO transformational leadership the new product development process. Leadersh. Organ. Dev. J. 2016, 37, 6-16. [CrossRef]

18. Naranjo Valencia, J.C.; Sanz Valle, R.; Jiménez Jiménez, D. Organizational culture as determinant of product innovation. Eur. J. Innov. Manag. 2010, 13, 466-480. [CrossRef]

19. Aksoy, H. How do innovation culture, marketing innovation product innovation affect the market performance of small medium-sized enterprises (SMEs). Technol. Soc. 2017, 51, 133-141. [CrossRef] 
20. Ghasemaghaei, M.; Calic, G. Assessing the impact of big data on firm innovation performance: Big data is not always better data. J. Bus. Res. 2020, 108, 147-162. [CrossRef]

21. Raza, S.; Minai, M.S.; Abrar ul Haq, M.; Zain, A.Y.M. Entrepreneurial network towards small firm performance through dynamic capabilities: The conceptual perspective. Acad. Entrep. J. 2018, 24, 1-9.

22. Borjesson, S.; Lofsten, H. Capabilities for innovation in small firms-A study of 131 high-tech firms their relation to performance. Int. J. Bus. Innov. Res. 2012, 6, 149-176.

23. Frishammar, J.; Cenamor, J.; Cavalli-Björkman, H.; Hernell, E.; Carlsson, J. Digital strategies for two-sided markets: A case study of shopping malls. Decis. Support Syst. 2018, 108, 34-44. [CrossRef]

24. Giotopoulos, I.; Kontolaimou, A.; Korra, E.; Tsakanikas, A. What drives ICT adoption by SMEs? Evidence from a large-scale survey in Greece. J. Bus. Res. 2017, 81, 60-69. [CrossRef]

25. Szabó-Szentgróti, G.; Végvári, B.; Varga, J. Impact of Industry 4.0 and Digitization on Labor Market for 2030-Verification of Keynes' Prediction. Sustainability 2021, 13, 7703. [CrossRef]

26. Williams, M.D.; Dwivedi, Y.K.; Lal, B.; Schwarz, A. Contemporary trends issues in IT adoption diffusion research. J. Inf. Technol. 2009, 24, 1-10. [CrossRef]

27. Mikalef, P.; Pateli, A. Information technology-enabled dynamic capabilities their indirect effect on competitive performance: Findings from PLS-SEM fsQCA. J. Bus. Res. 2017, 70, 1-16. [CrossRef]

28. Teece, D.J. Profiting from innovation in the digital economy: Enabling technologies, stards, licensing models in the wireless world. Res. Policy 2018, 47, 1367-1387. [CrossRef]

29. Helfat, C.E.; Raubitschek, R.S. Dynamic integrative capabilities for profiting from innovation in digital platform-based ecosystems. Res. Policy 2018, 47, 1391-1399. [CrossRef]

30. Dominguez Gonzalez, R.V.; Massaroli de Melo, T. The effects of organization context on knowledge exploration exploitation. J. Bus. Res. 2018, 90, 215-225. [CrossRef]

31. Zeng, S.X.; Xie, X.M.; Tam, C.M. Relationship between cooperation networks innovation performance of SMEs. Technovation 2010, 30, 181-194. [CrossRef]

32. Pesce, D.; Neirotti, P.; Paolucci, E. When culture meets digital platforms: Value creation stakeholders' alignment in big data use. Curr. Issues Tour. 2019, 22, 1883-1903. [CrossRef]

33. Vey, K.; Fel-Meyer, T.; Zipp, J.S.; Schneider, C. Learning \& Development in Times of Digital Transformation: Facilitating a Culture of Change Innovation. Int. J. Adv. Corp. Learn. 2017, 10, 1-11.

34. Fitzgerald, M.; Kruschwitz, N.; Bonnet, D.; Welch, M. Embracing digital technology: A new strategic imperative. MIT Sloan Manag. Rev. 2014, 55, 1-11.

35. Kline, S.; Dyer-Witheford, N.; De Peuter, G. Digital Play: The Interaction of Technology, Culture, Marketing; McGill-Queen's Press-MQUP: Montreal, QC, Canada, 2003.

36. Globocnik, D.; Rauter, R.; Baumgartner, R.J. Synergy or conflict? The relationships among organisational culture, sustainabilityrelated innovation performance, economic innovation performance. Int. J. Innov. Manag. 2020, 24, 2050004. [CrossRef]

37. Lijauco, F.; Gajendran, T.; Brewer, G.; Rasoolimanesh, S.M. Impacts of culture on innovation propensity in small to medium enterprises in construction. J. Constr. Eng. Manag. 2020, 146, 04019116. [CrossRef]

38. Halim, H.A.; Ahmad, N.H.; Ramayah, T.; Hanifah, H.; Taghizadeh, S.K.; Mohamad, M.N. Towards an innovation culture: Enhancing innovative performance of Malaysian SMEs. Acad. J. Interdiscip. Stud. 2015, 4, 85-97.

39. Padilha, C.K.; Gomes, G. Innovation culture performance in innovation of products processes: A study in companies of textile industry. RAI Rev. Adm. E Inovação 2016, 13, 285-294. [CrossRef]

40. Chen, Z.; Huang, S.; Liu, C.; Min, M.; Zhou, L. Fit between organizational culture innovation strategy: Implications for innovation performance. Sustainability 2018, 10, 3378. [CrossRef]

41. Ghasemzadeh, P.; Nazari, J.A.; Farzaneh, M.; Mehralian, G. Moderating role of innovation culture in the relationship between organizational learning innovation performance. Learn. Organ. 2019, 26, 233-245. [CrossRef]

42. Vorhies, D.W.; Morgan, N.A. Benchmarking marketing capabilities for sustained competitive advantage. J. Mark. 2005, 69, 80-94. [CrossRef]

43. Zhu, K. The complementarity of information technology infrastructure and ecommerce capability: A resource-based assessment of their business value. J. Manag. Inf. Syst. 2004, 2, 167-202. [CrossRef]

44. Burd, S. E-Commerce Transformation in Australia and New Zealand: Perspective and Insights from CEOs and Senior Executives of the Top 1000 Firms in Australia and New Zealand; Cap Gemini Ernst \& Young: Sydney, Australia, 2001.

45. Herhausen, D.; Miočević, D.; Morgan, R.E.; Kleijnen, M.H. The digital marketing capabilities gap. Ind. Mark. Manag. 2020, 90, 276-290. [CrossRef]

46. Prasad, V.K.; Ramamurthy, K.; Naidu, G.M. The influence of internet-marketing integration on marketing competencies and export performance. J. Int. Mark. 2001, 9, 82-110. [CrossRef]

47. Rai, A.; Tang, X. Leveraging IT capabilities competitive process capabilities for the management of interorganizational relationship portfolios. Inf. Syst. Res. 2010, 21, 516-542. [CrossRef] 
48. Terziovski, M. Innovation practices its performance implications in small medium enterprises (SMEs) in the manufacturing sector: A resource-based view. Strateg. Manag. J. 2010, 31, 892-902. [CrossRef]

49. Alegre, J.; Chiva, R. Assessing the impact of organizational learning capability on product innovation performance: An empirical test. Technovation 2008, 28, 315-326. [CrossRef]

50. Preacher, K.J.; Hayes, A.F. Asymptotic resampling strategies for assessing comparing indirect effects in multiple mediator models. Behav. Res. Methods 2008, 40, 879-891. [CrossRef]

51. Yousaf, Z.; Radulescu, M.; Sinisi, C.I.; Serbanescu, L.; Păunescu, L.M. Towards sustainable digital innovation of SMEs from the developing countries in the context of the digital economy and frugal environment. Sustainability 2021, 13, 5715. [CrossRef] 